\title{
Knockdown resistance in Anopheles vagus, An. sinensis, An. paraliae and An. peditaeniatus populations of the Mekong region
}

\author{
Katrijn Verhaeghen ${ }^{1}$, Wim Van Bortel ${ }^{1}$, Ho Dinh Trung ${ }^{2}$, Tho Sochantha ${ }^{3}$, Kalouna Keokenchanh ${ }^{4}$, \\ Marc Coosemans ${ }^{1,5^{*}}$
}

\begin{abstract}
Background: In the Mekong region (Vietnam, Cambodia and Laos), a large investigation was conducted to assess the susceptibility of Anopheles species against DDT and pyrethroids. In this study, the resistance status of the potential malaria vectors An. vagus, An. sinensis, An. paraliae and An. peditaeniatus was assessed.

Methods: Bioassays were performed on field collected unfed female mosquitoes using the standard WHO susceptibility tests. In addition, the DIIS6 region of the para-type sodium channel gene was amplified and sequenced and four allele-specific PCR assays were developed to assess the $k d r$ frequencies.

Results: In Southern Vietnam all species were DDT and pyrethroid resistant, which might suggest the presence of a $k d r$ resistance mechanism. Sequence-analysis of the DIIS6 region of the para-type sodium channel gene revealed the presence of a L1014S kdr mutation in An. vagus, An. sinensis and An. paraliae. In An. peditaeniatus, a low frequency L1014S kdr mutation was found in combination with a high frequency L1014F kdr mutation. For pyrethroids and DDT, no genotypic differentiation was found between survivors and non-survivors for any of these species. In the two widespread species, An. vagus and An. sinensis, kdr was found only in southern Vietnam and in Cambodia near the Vietnamese border.

Conclusions: Different levels of resistance were measured in Laos, Cambodia and Vietnam. The kdr mutation in different Anopheles species seems to occur in the same geographical area. These species breed in open agricultural lands where malaria endemicity is low or absent and vector control programs less intensive. It is therefore likely that the selection pressure occurred on the larval stages by insecticides used for agricultural purposes.
\end{abstract}

\section{Background}

Insecticide resistance may jeopardize the enormous malaria control efforts which have resulted in a significant decrease in the malaria burden in the Mekong region [1]. Insects may survive the toxic effect of insecticides by different resistance mechanisms. The major mechanisms involve either mutations within the target site of the insecticide or an alteration in the rate of insecticide detoxification. The para-type sodium channel is the target for both pyrethroids and DDT and mutations in this gene have been linked to knockdown resistance $(k d r)$ in several insects [2]. In the malaria vector

\footnotetext{
* Correspondence: mcoosemans@itg.be

'Department of Parasitology, Institute of Tropical Medicine Antwerp, Nationalestraat 155, B-2000 Antwerpen, Belgium
}

Anopheles gambiae sensu lato, two different mutations at codon 1014 of domain II of the sodium channel gene have been associated with knockdown resistance. The first mutation involves a point mutation resulting in a leucine-to-phenylalanine (L1014F) substitution, whereas a second mutation results in a leucine-to-serine (L1014S) substitution [3,4]. Recently, a leucine-tocysteine (L1014C) substitution was found in permethrin resistant An. sinensis populations of Korea [5]. In the detoxification of insecticides, different enzyme families are involved and elevated levels of esterases, monooxygenases and glutathione-S-transferases (GST) have been linked with insecticide resistance in Anopheles [6-9].

In the Mekong countries, a large investigation has been conducted to assess the susceptibility of different
C Biomed Central

(c) 2010 Verhaeghen et al; licensee BioMed Central Ltd. This is an Open Access article distributed under the terms of the Creative Commons Attribution License (http://creativecommons.org/licenses/by/2.0), which permits unrestricted use, distribution, and reproduction in any medium, provided the original work is properly cited. 
Anopheles species against pyrethroid insecticides and DDT. Amongst the main malaria vectors, Anopheles epiroticus was highly pyrethroid resistant in the Mekong delta, whereas An. minimus s.l. was pyrethroid resistant in some localities in northern Vietnam [10]. A low level of phenotypic pyrethroid resistance was found in An. dirus sensu stricto from central Vietnam [10]. In these main malaria vectors no $k d r$ mutation was observed [11].

Here, the resistance status of the potential vectors $A n$. vagus, An. sinensis, An. paraliae and An. peditaeniatus was assessed. These species are abundant in the Mekong region and despite their zoophilic trend they regularly bite humans [12] and can play a role in the maintenance of malaria at low or epidemic level [13]. An. sinensis contributes to low malaria endemicity in the plains of China [14] and epidemics in North Korea [15]. Based on positive CSP ELISA tests on head and thorax, An vagus has been suspected as malaria vector in Bangladesh $[16,17]$, Sri Lanka [13] and in the Assam state of India [18]. Similarly An. peditaeniatus was found ELISA positive in Thailand [19] and Sri Lanka [13]. An. paraliae and $A n$. sinensis are genetically closely related and can be easily confused on morphological characters. $A n$. sinensis and An peditaeniatus are also vectors of Brugia malayi $[20,21]$. All these species breed in open agricultural lands, like rice fields [22-24] and can be considered as indicator species for insecticide pressure from agricultural origins. In this study, the role of $k d r$ mutations in the different resistant An. vagus, An. sinensis, $A n$. paraliae and $A n$. peditaeniatus populations of the Mekong region was assessed.

\section{Materials and methods}

\section{Mosquito collections and bioassays}

Bioassays were done in the framework of a cross country survey on insecticide resistance in the Mekong region [10]. The list of the study sites with coordinates is giving in Additional file 1. Briefly, from 2003 until 2005 adult female mosquitoes were collected by different collection methods throughout Vietnam, Cambodia and Laos and identified morphologically in the field by use of a standardized key for medically important anophelines [25]. Bioassays were performed using the standard WHO susceptibility test kit with diagnostic concentrations of $0.75 \%$ permethrin and $4 \%$ DDT [26]. The bioassays were done on adult collected unfed female mosquitoes meaning that the age of the tested specimens was unknown. Additional bioassays were performed with diagnostic concentrations of type II pyrethroids $\left(0.05 \%\right.$ lambda-cyhalothrin, $0.082 \%\left(30 \mathrm{mg} / \mathrm{m}^{2}\right)$ alpha-cypermethrin or $0.05 \%$ deltamethrin) and $0.5 \%$ etofenprox. Impregnated and control papers were supplied by the Vector Control Research Unit, Universiti
Sains Malaysia. The exposure time was $60 \mathrm{~min}$ with tubes maintained in the vertical position. After exposure, mosquitoes were kept under observation for $24 \mathrm{~h}$ and supplied with $10 \%$ sugar solution. Mortality was read after this $24 \mathrm{~h}$ period and corrected by Abbott's formula, if the control mortality was between 5 and $20 \%$ [26]. The bioassay results were divided into three mortality categories according to the WHO criteria [26]. A $24 \mathrm{~h}$ post-exposure mortality less than $80 \%$ indicates resistance, whereas a mortality higher than $98 \%$ indicates susceptibility. Intermediate mortality levels suggest the possibility of resistance that needs to be confirmed. After the bioassays, the mosquitoes were dried over silica gel.

\section{Species identification}

One to six legs of individual mosquitoes were used for genomic DNA extraction, applying the procedure described in Collins et al. [27]. DNA was resuspended in $25 \mu \mathrm{l} \mathrm{TE}$ buffer $(10 \mathrm{mM}$ Tris- $\mathrm{HCl} \mathrm{pH} 8 ; 1 \mathrm{mM}$ EDTA). A negative control was included with every set of extractions. The identification of An. vagus, $A n$. sinensis, An. paraliae and An. peditaeniatus specimens of which the DIIS6 region of the para-type sodium channel gene was sequenced, was confirmed by sequencing of the ITS2 rDNA gene using the primers described in Van Bortel et al. [28].

\section{Detection of $k d r$ mutations}

Primers Agd1 and Agd2 [3] were used to amplify the DIIS6 region $(k d r$ - region or transmembrane segment 6 of the domain II) of the para-type sodium channel gene for An. vagus, whereas primers Agd1Mi and $\mathrm{Agd} 2 \mathrm{H}$ (Figure 1) amplified the DIIS6 region for An. sinensis, An. paraliae and An. peditaeniatus. Amplification was performed in a $50 \mu \mathrm{l}$ reaction containing $1 \mu \mathrm{l}$ of template DNA, $1 \times$ Qiagen PCR buffer, $1 \mathrm{mM} \mathrm{MgCl} 2,200$ $\mu \mathrm{M}$ of each dNTP, $100 \mathrm{nM}$ of each primer and 1 unit Taq DNA polymerase (Taq PCR core kit, Qiagen, Hilden, Germany).

The cycling conditions were as follows: initial denaturation at $94^{\circ} \mathrm{C}$ for $3 \mathrm{~min}, 40$ cycles of 1 min denaturation at $94^{\circ} \mathrm{C}, 30 \mathrm{~s}$ annealing at $47^{\circ} \mathrm{C}$ and $30 \mathrm{~s}$ extension at $72^{\circ} \mathrm{C}$ followed by a final extension of $10 \mathrm{~min}$ at $72^{\circ} \mathrm{C}$. Amplification products were checked on a $2 \%$ agarose gel, stained with ethidium bromide and visualised on the Syngene Ingenius LHR (Westburg, Leusden, The Netherlands). The resulting PCR product was cloned by use of the Original TA cloning kit according to the manufacturer's instructions (Invitrogen, Carlsbad, California). Plasmid and direct PCR sequencing were done by the VIB genetic service facility (University of Antwerp, Belgium) and aligned with ClustalW version 1.3 [29]. 


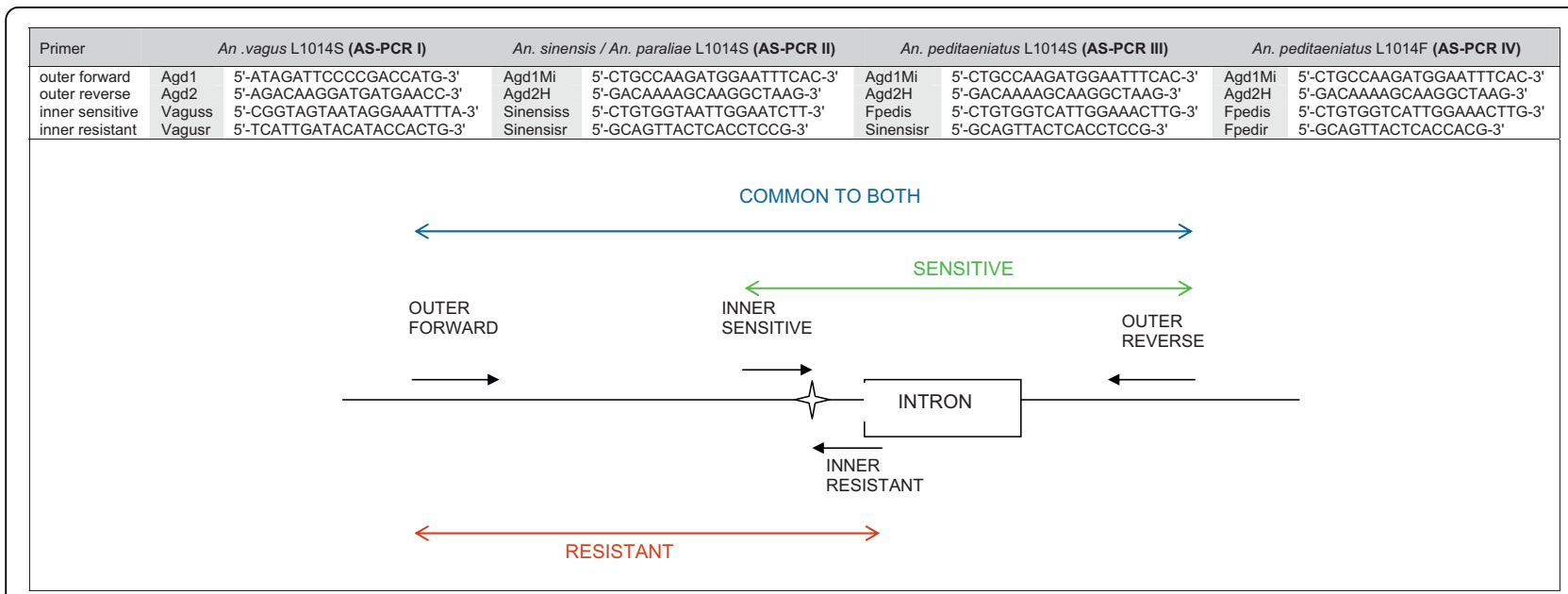

Figure 1 Schematic representation and the primer sequences of the AS-PCRs used to detect the L1014S kdr mutation in An. vagus (AS-PCR I), An. sinensis (AS-PCR II), An. paraliae (AS-PCR II), An. peditaeniatus (AS-PCRIII) and the L1014F kdr mutation in An.

peditaeniatus (AS-PCR IV). The figure represents the DIIS6 region of the sodium channel gene. The intron is represented by a box and codon 1014 is indicated by a star graphic.

The DIIS6 sequences were used to develop primers for four allele-specific PCR assays (AS-PCRs) to assess the $k d r$ frequencies in the different Anopheles populations. An additional A was added to 3'-end of the primer Vaguss in order to minimize self-complementarity and additional mismatch bases were introduced in the Sinensiss and Sinensisr primers at the $4^{\text {th }}$ nucleotide from the 3'-end (A was replaced by T) to obtain more specific results (Figure 1). The AS-PCR assays were optimized by running genomic DNA templates that had been previously genotyped by DNA sequencing. All ASPCR assays were performed in a $50 \mu \mathrm{l}$ reaction mixture containing: $1 \times$ Qiagen PCR buffer, $1 \times \mathrm{Q}$ solution, 0.5 $\mathrm{mM} \mathrm{MgCl} 2,200 \mu \mathrm{M}$ dNTP's, $400 \mathrm{nM}$ of the outer forward and reverse primer, $500 \mathrm{nM}$ of the inner resistant and sensitive primer (Figure 1), 1 unit Taq DNA polymerase (Qiagen, Hilden, Germany) and $1 \mu$ l template. The cycling conditions described above for the amplification of the DIIS6 region were used. The amplification products were electrophoresed on a $3 \%$ mixed agarose gel (1.5\% agarose and $1.5 \%$ small fragment agarose) and visualised under UV light after ethidium bromide staining. In each assay, a sequenced heterozygote resistant mosquito was run with the AS-PCR as positive control.

The $k d r$ genotype frequencies of mosquitoes exposed to WHO bioassay were compared for dead and surviving using the exact tests for population differentiation in Genepop (version 3.4) [30].

\section{Results}

Bioassays

Details of the bioassays can be found in Additional file 2. DDT resistance was widespread over the An. vagus populations of Laos, Cambodia and Vietnam. In Laos and northern Vietnam, the An. vagus populations remained pyrethroid susceptible. In Cambodia, the $A n$. vagus populations were pyrethroid susceptible or tolerant. In southern Vietnam, the pyrethroid resistance increased and a combination of DDT and pyrethroid resistance was found (Figure 2).

The Vietnamese An. sinensis populations were possibly DDT resistant. In southern Vietnam, a combination of DDT and pyrethroid resistance was found for An. sinensis, An. paraliae and An. peditaeniatus (Figure 3).

\section{Kdr mutations}

Sequences of the DIIS6 region of the para-type sodium channel gene were obtained for both, live and dead $A n$. vagus $(\mathrm{n}=65)$, An. sinensis $(\mathrm{n}=33)$, An. paraliae $(\mathrm{n}=21)$ and $A n$. peditaeniatus $(\mathrm{n}=87)$ mosquitoes. In pyrethroid and DDT resistant An. vagus, An. sinensis and An. paraliae populations, a leucine-to-serine replacement at codon 1014 was observed. In An. peditaeniatus, both a leucineto-phenylalanine and a leucine-to-serine replacement were detected at codon 1014. The last amino acid replacement was only detected in combination with the L1014F mutation. To confirm the presence of both $k d r$ alleles in An. peditaeniatus individuals, cloning and plasmid sequencing was performed (Figure 4).

In order to determine the $k d r$ frequencies in the Southeast Asian Anopheles populations, four different PCR assays were developed to detect the L1014S in An. vagus (AS-PCR I), An. sinensis and An. paraliae (AS-PCR II), An. peditaeniatus (AS-PCR III) and the L1014F $k d r$ mutation in An. peditaeniatus (AS-PCR IV). For the detection of the L1014S mutation, an internal 


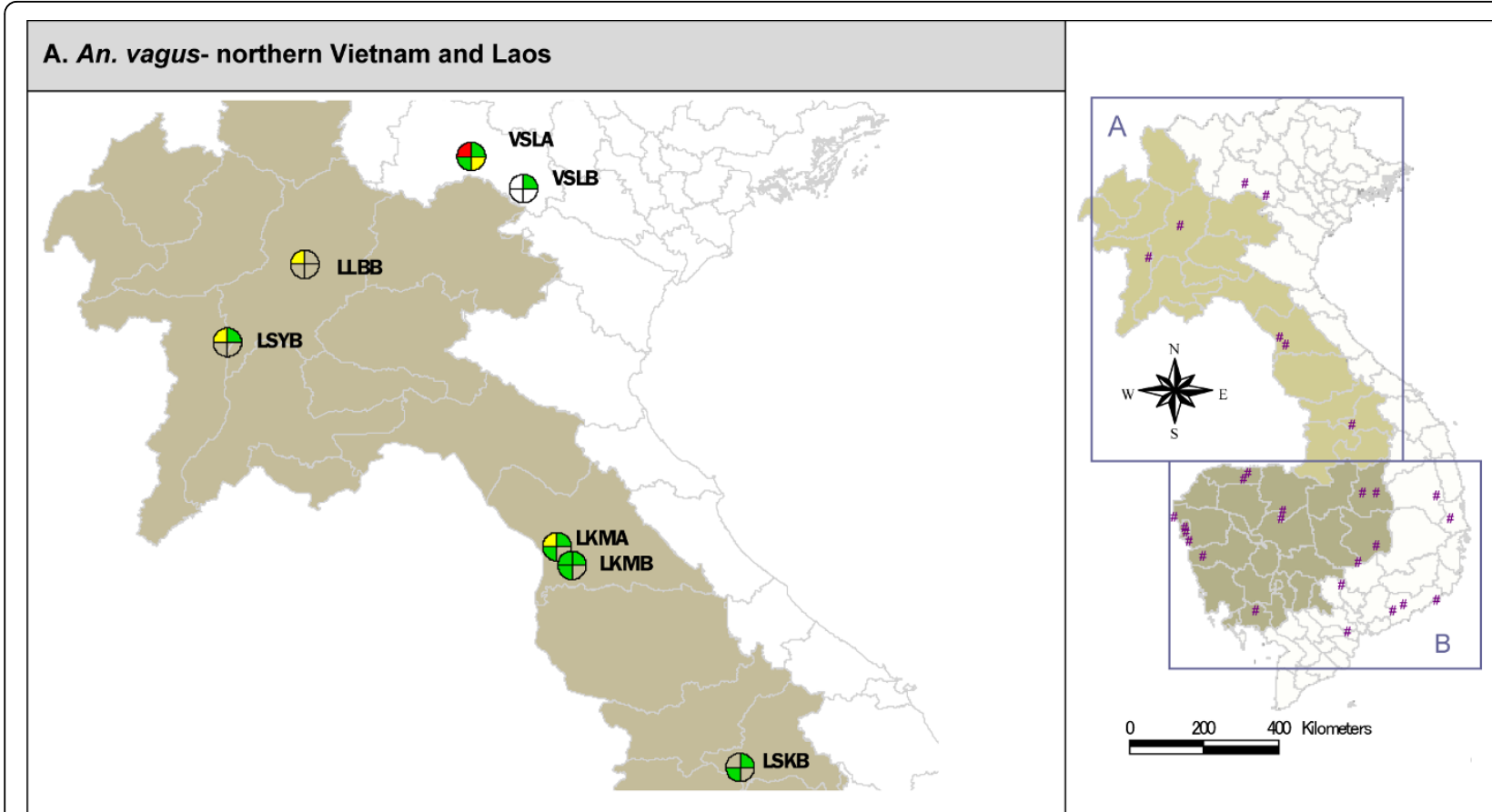

B. An. vagus - southern Vietnam and Cambodia

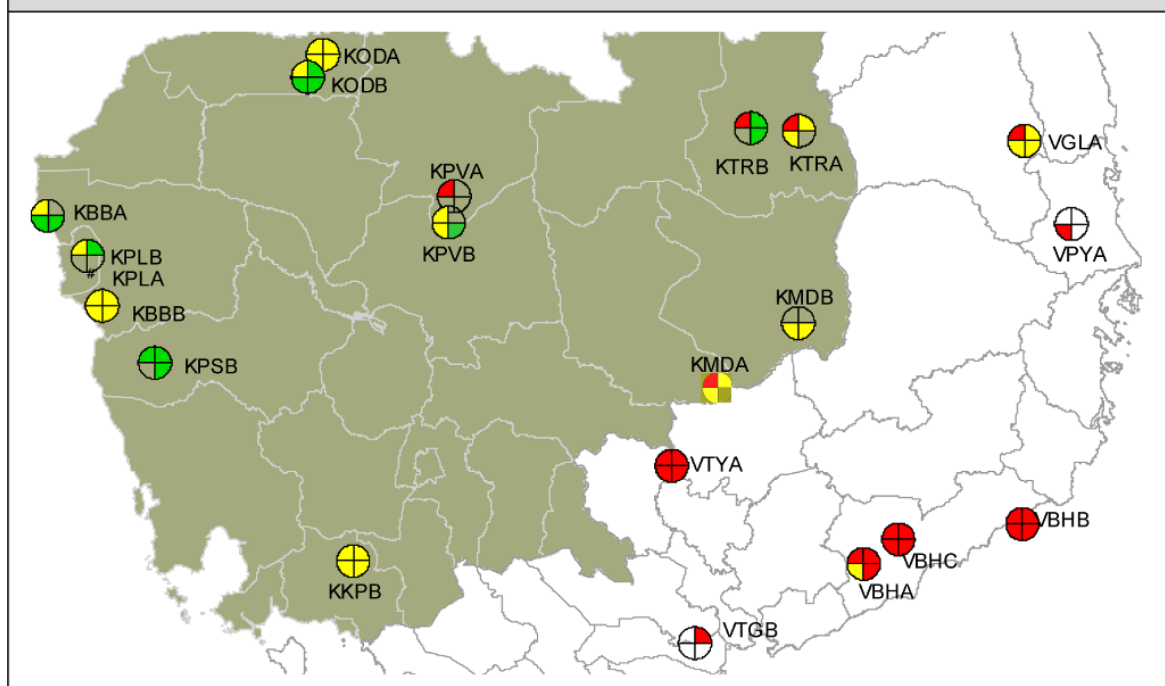

KPLA 2003

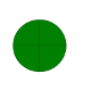

KPLA 2004

- Susceptible (mortality $98-100 \%)$

Possibility of resistance (mortality between $80-97 \%$ )

Resistant (mortality <80\%)

Not tested in bioassay

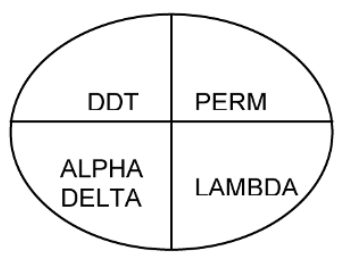

Figure 2 Mortality categories obtained for the An. vagus populations of Vietnam, Laos and Cambodia. The first quartile (right, up) represents the results obtained with $0.75 \%$ permethrin (PERM). In clockwise direction, results with discriminating concentrations of lambdacyhalothrin (LAMBDA), alpha-cypermethrin (ALPHA) (Vietnam) or deltamethrin (DELTA) (Cambodia and Laos) and DDT are given. The number of exposed mosquitoes varied from 20 (KPSB, lambda-cyhalothrin)* to 296 (LSYB, DDT). * LKMA (perm, delta, alpha); LKMB (perm, delta), KPSB (perm), KPLA (lambda), KTRB (lambda): number of exposed mosquitoes $<20$. 


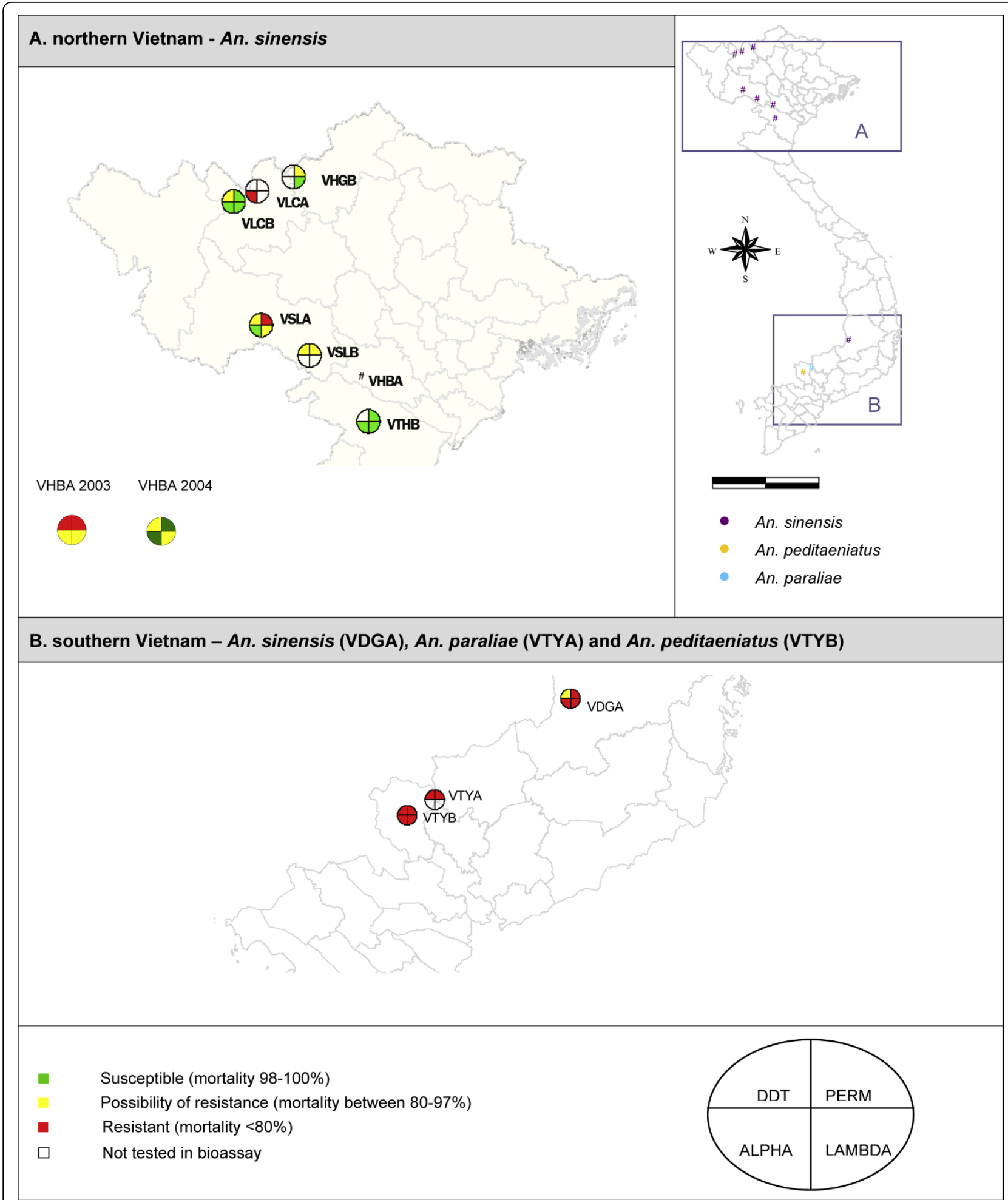

Figure 3 Mortality categories obtained for An. sinensis, An. paraliae and An. peditaeniatus. The first quartile (up right) represents the results obtained with $0.75 \%$ permethrin (PERM). In clockwise direction, results with discriminating concentrations of lambda-cyhalothrin (LAMBDA), alpha-cypermethrin (ALPHA) and DDT are given. The number of exposed An. sinensis varied from 20* (VTYA, permethrin) to 113 (VLCA, alpha-cypermethrin; VTHB, lambda-cyhalothrin) whereas the number of exposed An. peditaeniatus varied from 100 to 105 . For each insecticide between 20 (VTYA, permethrin) and 73 (VTYA, DDT) An. paraliae mosquitoes were exposed. * VHGB (perm): number of exposed mosquitoes $<20$. 


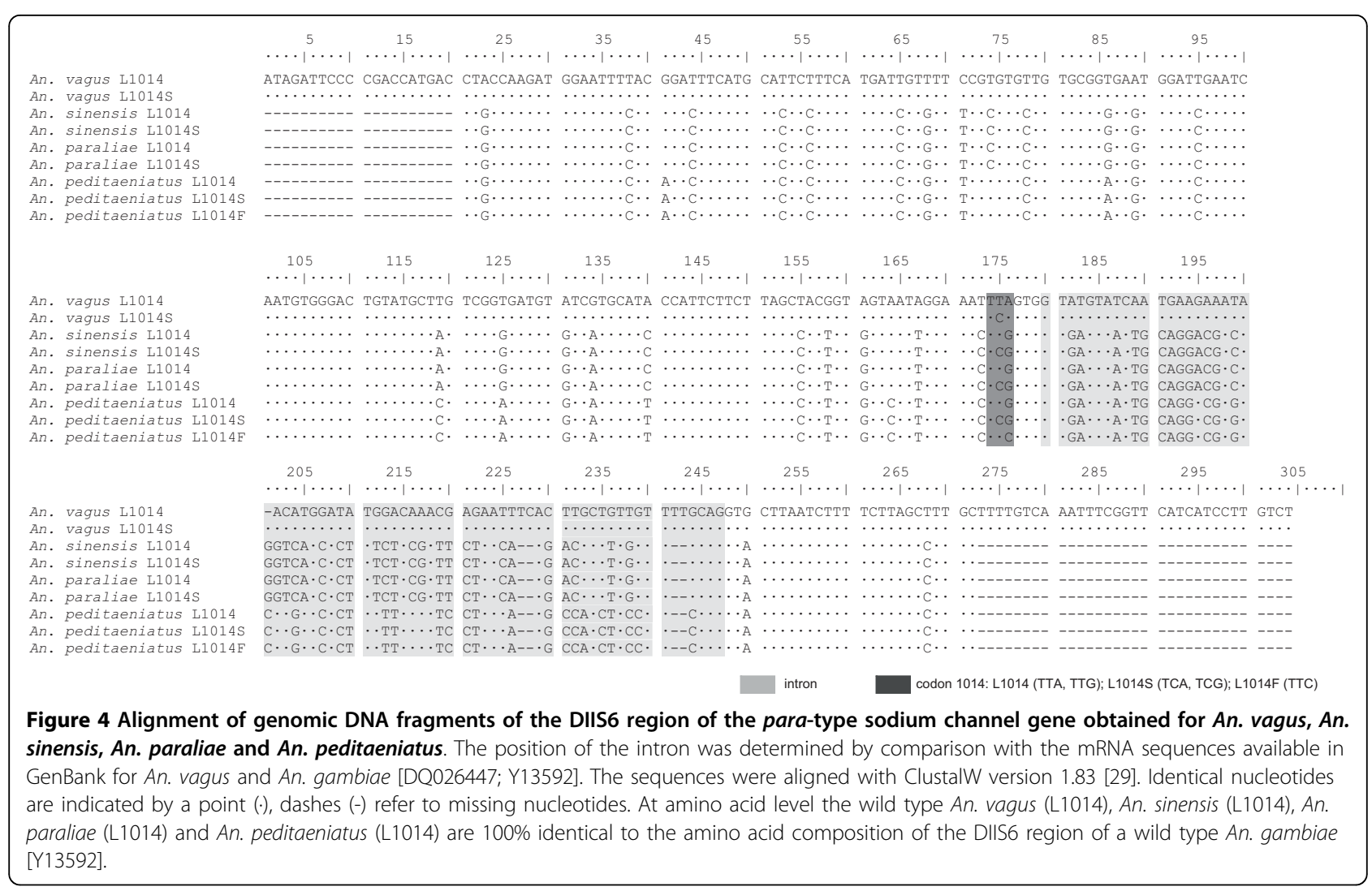

control band (303 bp for An. vagus; 255 bp for $A n$. sinensis, An. paraliae and An. peditaeniatus), a specific band for the L1014S $k d r$ allele (194 bp in An. vagus, $171 \mathrm{bp}$ in An. sinensis, An. paraliae and An. peditaeniatus) and a band for the wild type L1014 allele were obtained (147 bp for An. vagus, 119 bp for An. sinensis, An. paraliae and An. peditaeniatus) (Figure 5). The ASPCR IV assay was designed to detect the L1014F $k d r$ mutation in An. peditaeniatus with a control band of $255 \mathrm{bp}$, a $171 \mathrm{bp}$ band for the L1014F allele and a 119 bp band for the wild type L1014 allele. The Fpedis primer (sensitive specific) of the AS-PRC IV assay can also anneal to the L1014S allele, hence the L1014S $k d r$ allele can be misrecognized as the wild type allele L1014. This non-specific annealing can occur because there is only one nucleotide mismatch between the second nucleotide from the 3'-end of primer Fpedis and the sequence of the L1014S allele (T-C mismatch). For this reason the results of both PCRs (AS-PCR III and IV) needed to be combined in order to genotype the An. peditaeniatus specimens correctly.

By use of these AS-PCRs, 3305 An. vagus mosquitoes of 28 populations throughout Vietnam, Laos and Cambodia were analysed for the presence of the L1014S $k d r$ mutation. The L1014S allele was found only in 7 populations in heterozygote form (L1014S/L1014 genotype) in southern Vietnam and in Cambodia near the
Vietnamese border with a frequency varying from $0.7 \%$ to $15.7 \%$ (Table 1 ). The highest $k d r$ frequency was reported in the VTGB population, which is the most southerly located An. vagus population. However, in VTGB the L1014S $k d r$ frequency is likely to be overestimated, because only specimens that survived the permethrin WHO bioassay were analysed, whereas in the other An. vagus populations, both bioassay survivors and non-survivors were tested.

By use of the AS-PCR II, 1058 An. sinensis specimens of 8 populations were genotyped for the L1014S mutation. The L1014S $k d r$ mutation was found only in one population of southern Vietnam at a low frequency (2.3\%) (Table 1). In the two widespread Anopheles species, An. vagus and An. sinensis, the geographical distribution of the L1014S $k d r$ mutation overlap in southern Vietnam (Figure 6). In An. paraliae, the L1014S $k d r$ mutation was found at a moderate level (32.8\%) in southern Vietnam (VTYA) (Table 1). In An. peditaeniatus of southern Vietnam (VTYB), the L1014F $k d r$ allele was observed at a high frequency $(97.6 \%, \mathrm{n}=446)$. The L1014S $k d r$ allele was only observed in combination with the L1014F $k d r$ allele at a low frequency $(0.3 \%)$ The three specimens with the L1014S/L1014F genotype survived the discriminative dosage of DDT or lambda-cyhalothrin in the bioassay (Table 2). 


\section{L1014S $k d r$ detection}

(A) An. vagus (B) An. sinensis and An. paraliae

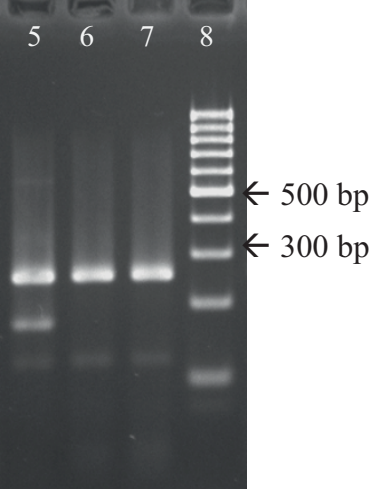

(C) An. peditaeniatus

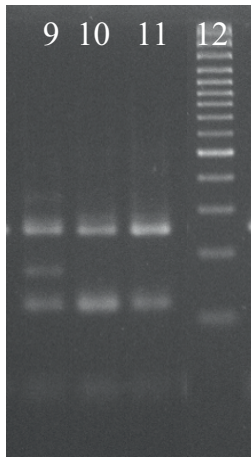

$\leftarrow 500$ bp

$\leftarrow 300$ bp

\section{L1014F kdr detection}

(D) An. peditaeniatus

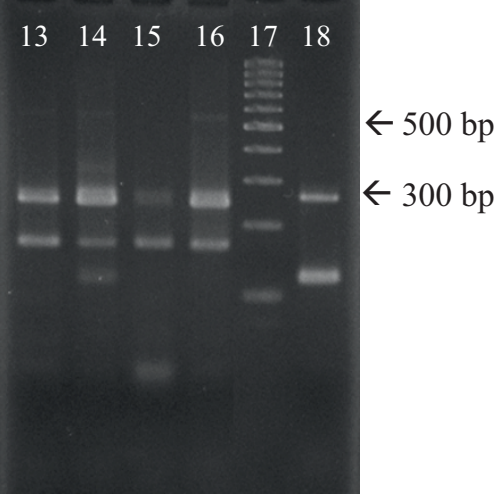

Figure 5 PCR fragments obtained using the different AS-PCRs after separation on a $\mathbf{3} \%$ mixed agarose gel. (A). Detection of the L1014S mutation in An. vagus (AS-PCR I). Lane 1:100 bp ladder; Lane 2: heterozygous specimens (L1014/L1014S); Lane 3 and 4: homozygous wild type mosquitoes (L1014/L1014). (B) Detection of the L1014S mutation in An. sinensis and An. paraliae (AS-PCR II). Lane 5: heterozygous specimens (L1014/L1014S); Lane 6 and 7: homozygous wild type mosquitoes (L1014/L1014); Lane 8: 100 bp ladder. (C) Detection of the L1014S mutation in An. peditaeniatus (AS-PCR III). Lane 9: heterozygous specimens (L1014/L1014S); Lane 10 and 11: homozygous wild type mosquitoes (L1014/L1014); Lane 8: 100 bp ladder. (D) Detection of the L1014F mutation in An. peditaeniatus (AS-PCR IV). Lane 13, 15 and 16: homozygous resistant specimen (L1014F/L1014F); Lane 14: heterozygous mosquito (L1014/L1014F); Lane 17: 100 bp ladder; Lane 18: homozygous wild type mosquito (L1014/L1014).

To assess the role of the $k d r$ mutations in conferring resistance, a comparison was made between the different $k d r$ genotypes and the survival status in the bioassay. For the four species, the different $k d r$ genotypes were equally distributed among bioassay survivors and nonsurvivors, even when homozygote resistant specimens were present (Table 2).

\section{Discussion}

From 2003 to 2005, WHO bioassays were performed on the An. vagus, An. sinensis, An. paraliae and An. peditaeniatus populations of Vietnam, Laos and Cambodia to assess their susceptibility to DDT and pyrethroids. Different levels of pyrethroid and DDT resistance were found. In the present bioassays, field collected females of unknown age were used, whereas the WHO protocol recommends the use of 1-3 day old females. As mortality in bioassays is significantly higher with old females compared with young ones [31] the results of the current study only underestimate the resistance problem.

In southern Vietnam, An. vagus, An. sinensis, An. peditaeniatus and $A n$. paraliae were highly resistant to both DDT and pyrethroids, which might suggest the presence of $k d r$. Sequences of the DIIS6 region of the para-type 
Table 1 Genotype and allele frequencies of the kdr alleles found in kdr resistant An. vagus, An. sinensis, An. paraliae and An. peditaeniatus populations

\begin{tabular}{|c|c|c|c|c|c|c|c|c|c|c|c|}
\hline \multirow[b]{2}{*}{$\begin{array}{l}\text { Anopheles } \\
\text { Species }\end{array}$} & \multirow[b]{2}{*}{$\begin{array}{l}\text { Study } \\
\text { site }\end{array}$} & \multirow[b]{2}{*}{ Number } & \multicolumn{6}{|c|}{ Genotype frequency (\%) } & \multicolumn{2}{|c|}{$\begin{array}{c}\text { Allele } \\
\text { frequency (\%) }\end{array}$} & \multirow[b]{2}{*}{$\begin{array}{l}\text { HWE p- } \\
\text { value }\end{array}$} \\
\hline & & & $\begin{array}{r}\text { L1014/ } \\
\text { L1014 }\end{array}$ & $\begin{array}{l}\text { L1014/ } \\
\text { L1014S }\end{array}$ & $\begin{array}{l}\text { L1014S/ } \\
\text { L1014S }\end{array}$ & $\begin{array}{l}\text { L1014S/ } \\
\text { L1014F }\end{array}$ & $\begin{array}{l}\text { L1014/ } \\
\text { L1014F }\end{array}$ & $\begin{array}{l}\text { L1014F/ } \\
\text { L1014F }\end{array}$ & L1014S & L1014F & \\
\hline \multirow[t]{7}{*}{ vagus } & KKPB & 214 & 98.13 & 1.87 & 0 & nd & nd & nd & 0.93 & nd & 1 \\
\hline & KMDA & 159 & 96.86 & 3.14 & 0 & nd & nd & nd & 1.57 & nd & 1 \\
\hline & VBHC & 469 & 93.60 & 6.40 & 0 & nd & nd & nd & 3.20 & nd & 1 \\
\hline & VGLA & 350 & 98.57 & 1.43 & 0 & nd & nd & nd & 0.71 & nd & 1 \\
\hline & VPYA & 91 & 97.80 & 2.20 & 0 & nd & nd & nd & 1.10 & nd & 1 \\
\hline & VTGB* & 35 & 68.57 & 31.43 & 0 & nd & nd & nd & 15.71 & nd & 0.5656 \\
\hline & VTYA & 405 & 95.31 & 4.69 & 0 & nd & nd & nd & 2.35 & nd & 1 \\
\hline sinensis & VDGA & 323 & 95.36 & 4.64 & 0 & nd & nd & nd & 2.32 & nd & 1 \\
\hline paraliae & VTYA & 61 & 47.55 & 39.34 & 13.11 & nd & nd & nd & 32.79 & nd & 0.3935 \\
\hline peditaeniatus & VTYB & 446 & 0.67 & nd & nd & 0.67 & 2.69 & 95.97 & 0.30 & 97.60 & 0.0006 \\
\hline
\end{tabular}

All bioassay survivors and non-survivors were analysed. Only populations where $k d r$ mutations were found are included in the table. Deviation from HardyWeinberg expectation (HWE - exact test using GENEPOP [30]). * Frequency based only on bioassay survivors. nd = not detected.

sodium channel gene, revealed the presence of a L1014S $k d r$ mutation in An. vagus, An. sinensis, An. paraliae and An. peditaeniatus and a L1014F $k d r$ mutation in $A n$. peditaeniatus. In the two widespread species, An. vagus and An. sinensis, knockdown resistance was observed only in Cambodia near the Vietnamese border and in southern Vietnam. In these species, the L1014S $k d r$ allele was found at a low frequency and only in the heterozygous form. In $A n$. paraliae, the L1014S $k d r$ frequency was higher and both heterozygous and homozygous resistant mosquitoes were observed. In An. peditaeniatus, the L1014S $k d r$ allele was very rare $(0.3 \%)$ and was found only in combination with the common L1014F $k d r$ allele (97.6\%). Interestingly, in An. gambiae s.s. of Uganda, Equatorial Guinea, Gabon and Cameroon, specimens were found to carry the same $k d r$ mutations in a heterozygous state (L1014F/L1014S genotype) [32-35].

For An. vagus, An. sinensis, An. paraliae and An. peditaeniatus, the different $k d r$ genotypes were equally distributed among bioassay survivors and non-survivors. For $A n$. vagus and An. sinensis this could be expected since $k d r$ is a recessive trait [36,37] and the L1014S $k d r$ mutation was only found in the heterozygous form. In An. paraliae, however, homozygous resistant L1014S/ L1014S mosquitoes were found and equally distributed among bioassay survivors and non-survivors. Also in the An. peditaeniatus population where the L1014F $k d r$ allele occurs at high allelic frequency, no connection was found between the genotype and resistant phenotype. In $A n$. peditaeniatus, even homozygous resistant L1014F/L1014F mosquitoes were found among the dead mosquitoes which suggest that beside the L1014F $k d r$ mutation other subsequent mutations in the para-type sodium channel gene might be needed for a mosquito to survive an exposure to a discriminating concentration of an insecticide. Such secondary mutations were found in Haematobia irritans and Musca domestica populations where super- $k d r$ mutations (M918T) in the DIIS4DIIS5 linker of the para-type sodium channel enhanced the pyrethroid resistance of individuals with the L1014F $k d r$ mutation [38,39]. Because in the present work only the DIIS6 region of the para-type sodium channel gene was sequenced, the presence of additional mutations in the para-type sodium channel gene can not be excluded. However, to date, no additional mutations were described in Anopheles species.

In the widespread $A n$. vagus and $A n$. sinensis, $k d r$ was geographically limited to an area in Southern Vietnam. In northern Vietnam, other resistance mechanisms could be involved. A limited number of populations were screened by biochemical assays (results not shown). Preliminary biochemical assays on DDT resistant $A n$. vagus and $A n$. sinensis populations revealed a high GST activity in Northern and Southern Vietnam. High esterase activity was found in pyrethroid resistant $A n$. vagus (VBHA and VBHB) and An. sinensis (VHBA 2003, VLCA, VSLA, VSLB) populations without $k d r$, whereas elevated levels of esterase activity were not detected in a $\mathrm{kdr}$ resistant population ( $A n$. vagus: VTYA) (data not shown). This shows that beside knockdown resistance, other mechanisms of insecticide resistance should be systematically explored.

Resistance to insecticides in malaria vectors has been often related to the use of insecticides in agronomy [40] 


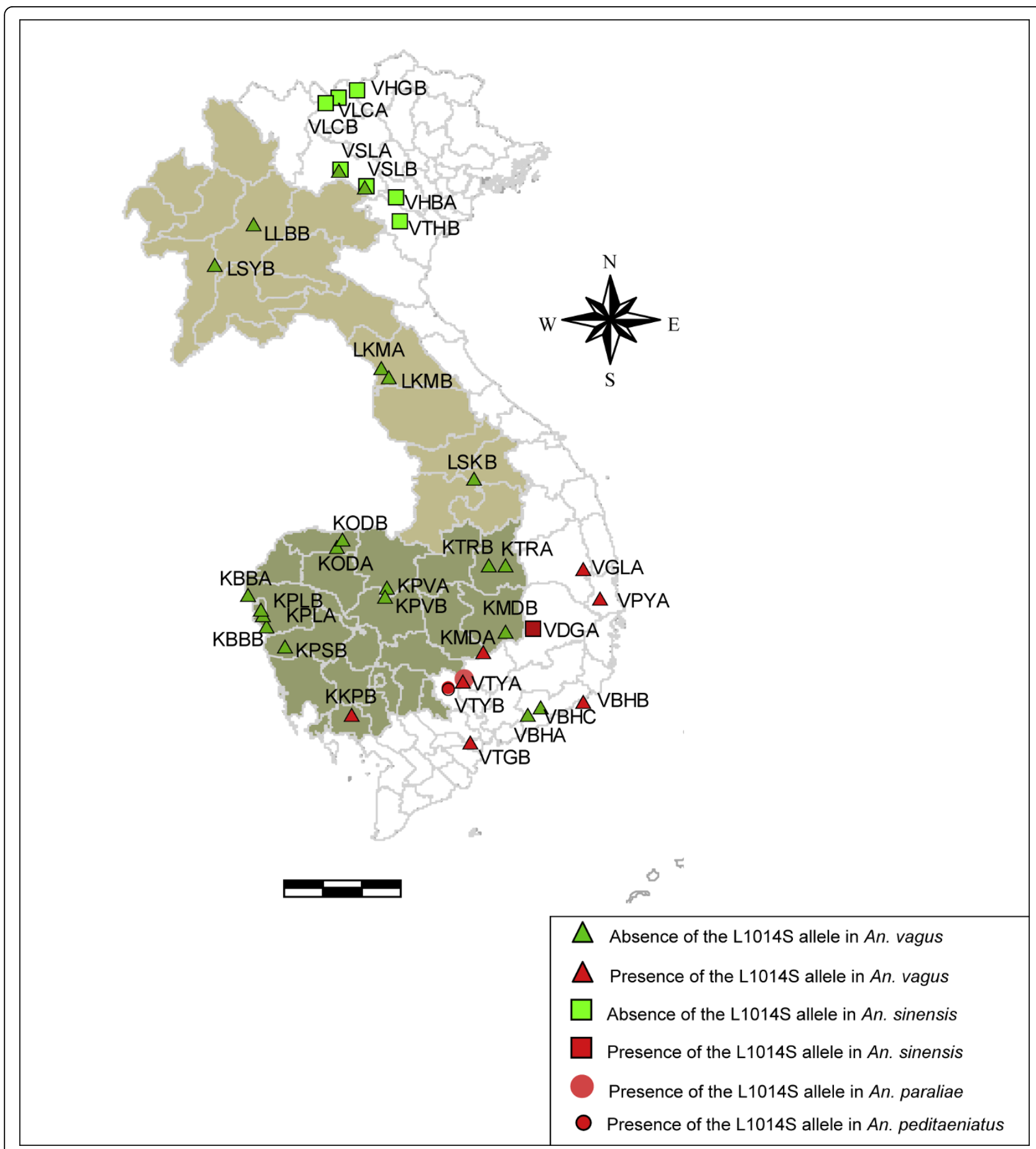

Figure 6 Geographical distribution of the L1014S kdr allele in An. vagus, An. sinensis, An. paraliae and An. peditaeniatus. For each population, at least 20 specimens were analyzed.

and seems most likely to have developed as a consequence of selection pressure on larvae [41]. The fact that in the same geographical area (southern Vietnam and Cambodia near the Vietnamese border) the $k d r$ resistance mechanism was selected in different Anopheles species (An. vagus, An. sinensis, An. paraliae and An. peditaeniatus) with a similar breeding ecology points in the same direction. An. vagus, An. sinensis, An. paraliae and An. peditaeniatus breed in rice fields $[22,23,42]$ which can be exposed to agricultural insecticides. In this study, investigators failed to collect correct information on pesticide use at household or communal level. However, in Vietnam, the 
Table 2 Genotype frequencies found for An. vagus, An. sinensis, An. paraliae and An. peditaeniatus

\begin{tabular}{|c|c|c|c|c|c|c|c|c|}
\hline \multirow[t]{2}{*}{ Species } & \multirow[t]{2}{*}{ Insecticide } & \multirow{2}{*}{$\begin{array}{c}\text { Alive } \\
\text { Dead }^{2}\end{array}$} & \multirow[t]{2}{*}{$\mathrm{N}$} & \multicolumn{4}{|c|}{$k d r$ genotype } & \multirow[t]{2}{*}{ p-value ${ }^{3}$} \\
\hline & & & & L1014/L1014 & L1014/L1014S & L1014S/L1014S & & \\
\hline \multirow[t]{8}{*}{ An. vagus ${ }^{\prime}$} & DDT & A & 160 & $93.75 \%$ & $6.25 \%$ & $0.00 \%$ & & 0.2297 \\
\hline & & $\mathrm{D}$ & 298 & $96.64 \%$ & $3.36 \%$ & $0.00 \%$ & & \\
\hline & PERMETHRIN & A & 105 & $87.86 \%$ & $12.14 \%$ & $0.00 \%$ & & 0.3844 \\
\hline & & $\mathrm{D}$ & 334 & $96.71 \%$ & $3.29 \%$ & $0.00 \%$ & & \\
\hline & ALPHA-CYPERMETHRIN & A & 134 & $94.78 \%$ & $5.22 \%$ & $0.00 \%$ & & 0.0970 \\
\hline & & $\mathrm{D}$ & 205 & $98.54 \%$ & $1.46 \%$ & $0.00 \%$ & & \\
\hline & LAMBDA-CYHALOTHRIN & A & 104 & $95.19 \%$ & $4.81 \%$ & $0.00 \%$ & & 0.7211 \\
\hline & & $\mathrm{D}$ & 103 & $97.09 \%$ & $2.91 \%$ & $0.00 \%$ & & \\
\hline \multirow[t]{8}{*}{ An. sinensis } & DDT & A & 16 & $93.75 \%$ & $6.25 \%$ & $0.00 \%$ & & 1.0000 \\
\hline & & $\mathrm{D}$ & 46 & $93.48 \%$ & $6.52 \%$ & $0.00 \%$ & & \\
\hline & PERMETHRIN & A & 44 & $90.91 \%$ & $9.09 \%$ & $0.00 \%$ & & 0.3642 \\
\hline & & $\mathrm{D}$ & 39 & $97.44 \%$ & $2.56 \%$ & $0.00 \%$ & & \\
\hline & ALPHA-CYPERMETHRIN & A & 40 & $97.50 \%$ & $2.50 \%$ & $0.00 \%$ & & 1.0000 \\
\hline & & $\mathrm{D}$ & 43 & $95.35 \%$ & $4.65 \%$ & $0.00 \%$ & & \\
\hline & LAMBDA-CYHALOTHRIN & A & 45 & $95.56 \%$ & $4.44 \%$ & $0.00 \%$ & & 1.0000 \\
\hline & & $\mathrm{D}$ & 31 & $96.77 \%$ & $3.23 \%$ & $0.00 \%$ & & \\
\hline \multirow[t]{5}{*}{ An. paraliae } & DDT & A & 21 & $38.09 \%$ & $42.86 \%$ & $19.05 \%$ & & 0.6918 \\
\hline & & $\mathrm{D}$ & 29 & $44.83 \%$ & $41.38 \%$ & $13.79 \%$ & & \\
\hline & PERMETHRIN & A & 30 & $50.00 \%$ & $50.00 \%$ & $0.00 \%$ & & 1.0000 \\
\hline & & D & 3 & $66.67 \%$ & $33.33 \%$ & $0.00 \%$ & & \\
\hline & & & & L1014/L1014 & L1014/L1014F & L1014F/L1014F & L1014F/L1014S & \\
\hline \multirow[t]{10}{*}{ An. peditaeniatus } & DDT & A & 93 & $1.08 \%$ & $6.45 \%$ & $90.32 \%$ & $2.15 \%$ & 0.7497 \\
\hline & & $\mathrm{D}$ & 7 & $0.00 \%$ & $0.00 \%$ & $100.00 \%$ & $0.00 \%$ & \\
\hline & PERMETHRIN & A & 74 & $1.35 \%$ & $0.00 \%$ & $98.65 \%$ & $0.00 \%$ & 1.0000 \\
\hline & & $\mathrm{D}$ & 12 & $0.00 \%$ & $0.00 \%$ & $100.00 \%$ & $0.00 \%$ & \\
\hline & ALPHA-CYPERMETHRIN & A & 77 & $0.00 \%$ & $2.60 \%$ & $97.40 \%$ & $0.00 \%$ & 0.3085 \\
\hline & & $\mathrm{D}$ & 10 & $0.00 \%$ & $10.00 \%$ & $90.00 \%$ & $0.00 \%$ & \\
\hline & LAMBDA-CYHALOTHRIN & A & 79 & $0.00 \%$ & $2.53 \%$ & $96.20 \%$ & $1.27 \%$ & 1.0000 \\
\hline & & $\mathrm{D}$ & 10 & $0.00 \%$ & $0.00 \%$ & $100.00 \%$ & $0.00 \%$ & \\
\hline & ETOFENPROX & A & 73 & $1.37 \%$ & $1.37 \%$ & $97.26 \%$ & $0.00 \%$ & 1.0000 \\
\hline & & $\mathrm{D}$ & 8 & $0.00 \%$ & $0.00 \%$ & $100.00 \%$ & $0.00 \%$ & \\
\hline
\end{tabular}

For An. vagus, the genotypes of the different populations could be pooled, because for each population the $k d r$ genotypes were equally distributed among the bioassay survivors and non-survivors (exact test for population differentiation using GENEPOP [30]). ${ }^{1}$ Pooled results for An. vagus populations of KMDA, KKPB, VBHC, VGLA, VPYA and VTYA. The An. vagus population of VTGB was excluded from the analysis, because only permethrin survivors were available. ${ }^{2}$ A: Alive, D: Dead; 24 hours after exposure to a discriminative dosage of an insecticide in a WHO bioassay. ${ }^{3}$ p-value of the genotypic differentiation between survivors and non-survivors (* correlation is significant at the 0.05 level) (Genepop; [30]).

pesticide use in rice fields accounted for $65.5 \%$ of the total market value of pesticides in 1996. The pesticide use was the highest in Southern Vietnam where there is a great tendency towards the application of cheaper, hazardous pesticides, including DDT $[43,44]$. The use of these insecticides in agriculture can explain why DDT resistance still exists in these vectors.

The complex insecticide resistance pattern varying with species and region demonstrates that insecticide resistance in Anopheles species of the Mekong region is a complex and dynamic process. Knowledge on the factors which determine insecticide resistance will be necessary to guide an efficient use of insecticides in both public health and agriculture.

\section{Additional material}

Additional file 1: Coordinates in Decimal Degree of the different collecting sites in Vietnam (V), Cambodia (K) and Laos (L).

Additional file 2: Details of the bioassays using the discriminating concentrations of insecticides: $4 \%$ DDT, $0.75 \%$ permethrin, $0.05 \%$ lambda-cyhalothrin, $0.082 \%\left(30 \mathrm{mg} / \mathrm{m}^{2}\right)$ alpha-cypermethrin, $0.05 \%$ deltamethrin, $05 \%$ etofenprox. Mortalities (after $24 \mathrm{~h}$ ) and proportion Knocked Down after 60 min exposure (in \%).

\section{Acknowledgements}

We acknowledge the excellent technical support of the entomological teams of the National Institute of Malariology, Parasitology and Entomology (NIMPE), Hanoi, Vietnam; the National Centre for Malaria 
Control, Parasitology and Entomology (NCMC), Phnom Penh, Cambodia and the Centre of Malariology, Parasitology and Entomology (CMPE), Vientiane, Laos; as well as the provincial malaria centers for their full and constant support to this study. We are grateful to the Ministries of Public Health of Vietnam, Laos and Cambodia for facilitating this research. We thank Valérie Obsomer (Université Catholique de Louvain, Louvain-laNeuve, Belgium) for providing maps of the Mekong region. This work was carried out within the framework of the INCO research project IC4CT2002-10041 and was supported by the Belgian Cooperation (Directoraat-Generaal voor Internationale Samenwerking, DGIS) in the framework of the Institutional Collaboration between ITM, Antwerp and NIMPE, Hanoi. This research was funded by a Ph.D. grant of the Institute for the Promotion of Innovation through Science and Technology in Flanders (IWT - Vlaanderen)

\section{Author details}

${ }^{1}$ Department of Parasitology, Institute of Tropical Medicine Antwerp, Nationalestraat 155, B-2000 Antwerpen, Belgium. ${ }^{2}$ Department of Entomology, National Institute of Malariology, Parasitology and Entomology, Luong The Vinh street, B.C. 10.200 Tu Liem, Hanoi, Vietnam. ${ }^{3}$ Department of Entomology, National Center for Malaria Control, Parasitology and Entomology, 372 Monivong Boulevard, Phnom Penh, Cambodia. ${ }^{4}$ Department of Entomology, Center of Malariology, Parasitology and Entomology, Kualuang Road, Vientiane, Laos. ${ }^{5}$ Department of Biomedical Sciences, Faculty of Pharmaceutical, Veterinary and Biomedical Sciences, University of Antwerp, Universiteitsplein 1, B-2610 Antwerpen (Wilrijk), Belgium

\section{Authors' contributions}

MC and WVB designed the study; revised and supervised the work at all stages. KV carried out the molecular work and drafted the manuscript. HDT, TS and KK supervised the bioassays in the field. All authors read and approved the final manuscript.

\section{Competing interests}

The authors declare that they have no competing interests.

Received: 11 June 2010 Accepted: 21 July 2010 Published: 21 July 2010

\section{References}

1. Coosemans M, Van Bortel W: Malaria vectors in the Mekong countries: a complex interaction between vectors, environment and human behaviour. Proc Internat Conf Hubs, Harbours and Deltas in Southeast Asia: Multidisciplinary and Intercultural Perspectives Royal Academy of Overseas Sciences Brussels 2007, 551-569.

2. Soderlund DM, Knipple DC: The molecular biology of knockdown resistance to pyrethroid insecticides. Insect Biochem Mol Biol 2003, 33:563-577.

3. Martinez-Torres D, Chandre F, Williamson MS, Darriet F, Bergé JB, Devonshire AL, Guillet P, Pasteur N, Pauron D: Molecular characterization of pyrethroid knockdown resistance $(k d r)$ in the major malaria vector Anopheles gambiae s.s.. Insect Mol Biol 1998, 7:179-184.

4. Ranson $H$, Jensen $B$, Vulule JM, Wang $X$, Hemingway J, Collins FH: Identification of a point mutation in the voltage-gated sodium channel gene of Kenyan Anopheles gambiae associated with resistance to DDT and pyrethroids. Insect Mol Biol 2000, 9:491-497.

5. Kim H, Baek JH, Lee WJ, Lee SH: Frequency detection of pyrethroid resistance allele in Anopheles sinensis populations by real-time PCR amplification of specific allele (rtPASA). Pestic Biochem Physiol 2007, 87:54-61.

6. Brogdon WC, MCAllister JC, Corwin AM, Cordon-Rosales C: Oxidase-based DDT-pyrethroid cross resistance in Guatemalan Anopheles albimanus. Pestic Biochem Physiol 1999, 64:101-111.

7. Vulule JM, Beach RF, Atieli FK, MCAllister JC, Brogdon WG, Roberts JM, Mwangi RW, Hawley WA: Elevated oxidase and esterase levels associated with permethrin tolerance in Anopheles gambiae from Kenyan villages using permethrin-impregnated nets. Med Vet Entomol 1999, 8:71-75.

8. Brooke BD, Kloke G, Hunt RH, Koekemoer LL, Temu EA, Taylor ME, Small G, Hemingway J, Coetzee M: Bioassay and biochemical analyses of insecticide resistance in southern African Anopheles funestus (Diptera: Culicidae). Bull Entomol Res 2001, 91:265-272.
9. Kostaropoulos I, Papadopoulos Al, Metaxakis A, Boukouvala E, Papadopoulou-Mourkidou E: Glutathione-S-transferase in the defence against pyrethroids in insects. Insect Biochem Mol Biol 2001, 31:313-319.

10. Van Bortel W, Trung HD, Thuan LK, Sochantha T, Socheat D, Sumrandee C, Baimai V, Koekenchanh K, Phompida S, Roelants P, Denis L, Verhaeghen K, Obsomer $V$, Coosemans $M$ : The insecticide resistance status of malaria vectors in the Mekong region. Malar J 2008, 7:102.

11. Verhaeghen K, Van Bortel W, Trung HD, Sochantha T, Coosemans M: Absence of knockdown resistance suggests metabolic resistance mechanisms in the Southeast Asian malaria vectors. Malar J 2009, 8:84.

12. Trung HD, Van Bortel W, Sochantha T, Keokenchanh K, Briet O, Coosemans M: Behavioural heterogeneity of Anopheles species in ecologically different localities in Southeast Asia: a challenge for vector control. Trop Med Int Health 2005, 10:251-262.

13. Amerasinghe $\mathrm{PH}$, Amerasinghe FP, Konradsen F, Fonseka KT, Wirtz RA: Malaria vectors in a traditional dry zone village in Sri Lanka. Am J Trop Med 1999, 60:421-429.

14. Manguin S, Carnevale P, Mouchet J, Coosemans M, Julvez J, Richard Lenoble D, Sircoulon J: Biodiversity of malaria in the world. Paris: John Libbey Eurotext 2008, 427.

15. Lee JS, Lee WJ, Cho SH, Ree HI: Outbreak of vivax malaria in areas adjacent to the demilitarized zone, South Korea, 1998. Am J Tropl Med Hyg 2002, 66:13-17.

16. Maheswary NP, Majumdar S, Chowdhury AR, Faruque MS, Montanari RM: Incrimination of An.vagus Donitz 1902 as an epidemic malaria vector in Bangladesh. Indian J Malariol 1994, 24:776-778.

17. Alam MS, Khan MGM, Chaudhury N, Deloer S, Nazib F, Bangali AM, Haque R: Prevalence of anopheline species and their Plasmodium infection status in epidemic-prone border areas of Bangladesh. Malar J 2010, 9:15.

18. Prakash A, Bhattacharyya DR, Mohapatra PK, Mahantha J: Role of the prevalent Anopheles species in the transmission of Plasmodium falciparum and P.vivax in Assam State, north-eastern India. Ann Trop Med Parasit 2004, 98:559-568.

19. Gingrich JB, Weatherhead A, Sattabongkot J, Pilakasiri C, Wirtz R: Hyperendemic malaria in a Thai village: dependence of year round transmission on focal and seasonally circumscribed mosquito (Diptera: Culicidae) habitats. J Med Entomol 1990, 27:1016-1026.

20. Zhang S, Cheng F, Webber R: A successful control programme for lymphatic filariasis in Hubei, China. Trans R Soc Trop Med Hyg 1994, 88:510-512.

21. Suzuki T, Sudomo M, Bang YH, Lim BL: Studies on Malayan filariasis in Bengkulu (Sumatra) Indonesia with special reference to vector confirmation. Southeast Asian J Trop Med Public Health 1981, 12:47-54.

22. Scanlon JE, Reid JA, Cheong WH: Ecology of Anopheles vectors of malaria in the Oriental region. Cah ORSTOM Sér Entomol Med Parasitol 1968, 6:237-246.

23. Mogi M, Miyagi I: Colonization of rice fields by mosquitoes (Diptera: Culicidae) and larvivorous predators in asynchronous rice cultivation areas in the Philippines. J Med Entomol 1990, 27:530-536.

24. Stoops CA, Gionar YR, Shinta, Sismadi P, Elyazar IRF, Bangs MJ, Sukowati S: Environmental factors associated with spatial and temporal distribution of Anopheles (Diptera: Culicidae) larvae in Sukabumi, West Java, Indonesia. J Med Entomol 2007, 44:543-553.

25. Ministry of Health National - Institute of Malariology, Parasitology and Entomology: Keysto the Anopheles in Vietnam. Medical Publishing House Hanoi, Vietnam 2008, 68.

26. WHO: Test procedures for insecticide resistance monitoring in malaria vectors, bio-efficacy and persistence of insecticides on treated surfaces. Document WHO/CDS/CPC/MAL/98.12 World Health Organization, Geneva 1998.

27. Collins FH, Mendez MA, Rasmussen MO, Mehaffey PC, Besansky NJ, Finnerty $V$ : A ribosomal RNA gene probe differentiates member species of the Anopheles gambiae complex. Am J Trop Med Hyg 1987, 37:37-41.

28. Van Bortel W, Trung HD, Roelants P, Harbach RE, Backeljau T, Coosemans M Molecular identification of Anopheles minimus s.l. beyond distinguishing the members of the species complex. Insect Mol Biol 2000, 9:335-340.

29. Thompson JD, Higgins DG, Gibson TI: CLUSTAL W: improving the sensitivity of progressive multiple sequence alignment through sequence weighting, positions-specific cap penalties and weight matrix choice. Nucleic Acids Res 1994, 22:4673-4680. 
30. Raymond M, Rousset F: Genepop (version 1.2), a population genetics software for exact tests and ecumenicism. J Hered 1995, 86:248-249.

31. Hodjati $\mathrm{MH}$, Curtis CF: Evaluation of the effect of mosquito age and prior exposure to insecticide on pyrethroid tolerance in Anopheles mosquitoes (Diptera: Culicidae). Bull Entomol Res 1999, 89:329-337.

32. Etang J, Fondjo E, Chandre F, Morlais I, Brengues C, Nwane P, Chouiabou M, Ndjemai $\mathrm{H}$, Simard F: First report of knockdown mutations in the malaria vector Anopheles gambiae from Cameroon. Am J Trop Med Hyg 2006, 74:795-797.

33. Pinto J, Lynd A, Elissa N, Donnelly MJ, Costa C, Gentile G, Caccone A, doRosàrio VE: Co-occurrence of East and West African $k d r$ mutations suggests high levels of resistance to pyrethroid insecticides in Anopheles gambiae from Libreville, Gabon. Med Vet Entomol 2006, 20:27-32.

34. Verhaeghen K, Van Bortel W, Roelants P, Backeljau T, Coosemans M: Detection of the East and West African $k d r$ mutation in Anopheles gambiae s.s. and An. arabiensis from Uganda using a new assay based on FRET/Melt Curve Analysis. Malar J 2006, 5:16.

35. Moreno M, Vicente JL, Cano J, Berzosa PJ, de Lucio A, Nzambo S, Bobuakasi L, Buatiche JN, Ondo M, Micha F, Do Rosario VE, Pinto J, Benito $A$ : Knockdown resistance mutations $(k d r)$ and insecticide susceptibility to DDT and pyrethroids in Anopheles gambiae from Equatorial Guinea. Trop Med Int Health 2008, 13:430-433.

36. Martinez-Torres D, Chevillon C, Brun-Barale A, Bergé JB, Pasteur N, Pauron D: Voltage-dependent $\mathrm{Na}+$ channels in pyrethroid-resistant Culex pipiens $\mathrm{L}$ mosquitoes. Pestic Sci 1999, 55:1012-1020.

37. Hemingway J, Ranson $\mathrm{H}$ : Insecticide resistance in insect vectors of human disease. Annu Rev Entomol 2000, 45:371-391.

38. Williamson MS, Martinez-Torres D, Hick CA, Devonshire AL: Identification of mutations in the housefly para-type sodium channel gene associated with knockdown resistance $(k d r)$ to pyrethroid insecticides. Mol Gen Genet 1996, 252:51-60.

39. Guerrero FD, Jamroz RC, Kammlah D, Kunz SE: Toxicological and molecular characterization of pyrethroid-resistant horn flies, Haematobia irritans: identification of $k d r$ and super-kdr point mutation. Insect Biochem Mol Biol 1997, 27:745-755.

40. Diabate A, Baldet T, Chandre F, Akogbeto M, Guiguemde TR, Darriet F, Brengues C, Guillet P, Hemingway J, Small GJ, Hougard JM: The role of agricultural use of insecticide in resistance to pyrethroids in Anopheles gambiae s.l. in Burkina Faso. Am J Trop Med Hyg 2002, 67:617-622.

41. Mzilahowa T, Ball AJ, Bass C, Morgan JC, Nyoni B, Steen K, Donnelly MJ, Wilding CS: Reduced susceptibility to DDT in field populations of Anopheles quadriannulatus and Anopheles arabiensis in Malawi: evidence for larval selection. Med Vet Entomol 2008, 22:258-263.

42. van der Hoek W, Sakthivadivel R, Renshaw M, Silver JB, Birley MH, Konradsen F: Alternate wet/dry irrigation in rice cultivation: A practical way to save water and control malaria and Japanese encephalitis? International Water Management Institute (IWMI), Colombo, Sri Lanka 2001, Research Report 47.

43. Tenenbaum D: The value of Vietnam. Environ Health Perspect 1996, 104:1280-1285.

44. Quyen PB, San NV, Nhan DD: Environmental pollution in Vietnam: analytical estimation and environmental priorities. Trends Analyt Chem $1995,14: 383-388$.

doi:10.1186/1756-3305-3-59

Cite this article as: Verhaeghen et al: Knockdown resistance in Anopheles vagus, An. sinensis, An. paraliae and An. peditaeniatus populations of the Mekong region. Parasites \& Vectors 2010 3:59.

\section{Submit your next manuscript to BioMed Central and take full advantage of:}

- Convenient online submission

- Thorough peer review

- No space constraints or color figure charges

- Immediate publication on acceptance

- Inclusion in PubMed, CAS, Scopus and Google Scholar

- Research which is freely available for redistribution

Submit your manuscript at www.biomedcentral.com/submit
Biomed Central 